\title{
ПРОФНИАКТИЧЕСКАЯ МЕДНЦИНА
}

\author{
О.в. Иванова ', М.Ф. Савченков ${ }^{2}$, Т.Г. Романова ${ }^{1}$
}

\section{ПРАКТИЧЕСКИЕ МЕРОПРИЯТИЯ ПО ОБЕСПЕЧЕНИЮ САНИТАРНО-ЭПИДЕМИОЛОГИЧЕСКОГО БЛАГОПОЛУЧИЯ НАСЕЛЕНИЯ РЕСПУБЛИКИ ХАКАСИЯ В ЧРЕЗВЫЧАЙНЫХ УСЛОВИЯХ}

\author{
1 Управление Роспотребнадзора по Республике Хакасия, Абакан, Россия \\ ${ }_{2}^{2}$ ГБОУ вПО “Иркутский государственный медицинский университет» Минздрава России, Иркутск, Россия
}

\begin{abstract}
В статье представлен анализ лабораторных исследований качества питьевой воды, проведенных вусловиях и при ликвидации последствий чрезвычайных ситуаций в Республике Хакасия в 2013-2015 годах. В работе использована методология санитарно-гигиенической экспертизы объектов окружающей среды. При оценке качества воды водоисточников, питьевой воды применялись бактериологические и санитарно-химические методы исследования. Показано, что имеется зависимость качества питьевой воды в зависимости от вида чрезвычайной ситуации.
\end{abstract}

Ключевые слова: питьевая вода, санитарно-эпидемиологическая обстановка, чрезвычайная ситуация, Республика Хакасия

\section{PRACTICAL MEASURES TO ENSURE SANITARY AND EPIDEMIOLOGICAL WELFARE OF THE POPULATION OF THE REPUBLIC OF KHAKASSIA}

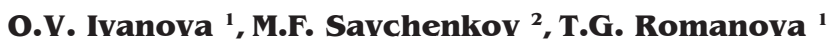 \\ ${ }^{1}$ Directorate of Rospotrebnadzor in the Republic of Khakassia, Abakan, Russia \\ ${ }^{2}$ Irkutsk State Medical University, Irkutsk, Russia
}

Three emergencies that occurred on the territory of the Republic of Khakassia, their potential influence on sanitary and epidemiological welfare of the population (using water factor as an example) were investigated. We used methods of data collection, analysis and further quality evaluation of fresh water. The results of 2956 analyses of fresh water from centralized sources of drinking water supply and water distribution network of the damaged areas were processed. It was determined that the most substantial deterioration of fresh water quality according to microbiological indicators was recorded in the flood period and upon the liquidation of the consequences of mass fire.

Key words: drinking water, sanitary and epidemiological situation, emergency, the Republic of Khakassia

\section{ВВЕДЕНИЕ}

Для начала XXI в. характерна тенденция к увеличению количества чрезвычайных ситуаций (ЧС) в мире и в нашей стране. Складывающаяся ситуация обусловлена как естественными, природными, причинами, так и результатом антропогенного воздействия на окружающую среду [4].

В период с 2003 по 2014 гг. в Российской Федерации зарегистрировано 4223 ЧС природного и 446 ЧС биолого-социального характера, пострадали десятки тысяч людей [7]. По данным того же источника, самые крупные в истории современной России ЧС природного характера произошли в Сибирском и Дальневосточном федеральных округах. Не исключением стала и Республика Хакасия. В течение трех лет на территории республики происходили различные ЧС: землетрясение, прохождение снего-дождевого паводка, осложнённого обильным выпадением осадков, массовые природные пожары. Данные ситуации обострили санитарно-эпидемиологическую обстановку и создали все условия к развитию чрезвычайной эпидемиологической ситуации.

\section{ЦЕЛЬ РАБОТЬ}

Оценка результатов исследований качества питьевой воды, проводимых как мера по обеспечению санитарно-эпидемиологического благополучия населения в чрезвычайных условиях.

\section{МЕТОДЫ И ОРГАНИЗАЦИЯ ИССЛЕДОВАНИЯ}

Изучались три чрезвычайных ситуации, произошедшие на территории Республики Хакасия, их возможное влияние на санитарно-эпидемиологическое благополучие населения (на примере водного фактора). Использованы данные социально-гигиенического мониторинга, инструментарием которого являются методы сбора данных, анализа и последующей оценки качества питьевой воды. Проанализировано 2956 проб питьевой воды, отобранной как из централизованных источников хозяйственнопитьевого водоснабжения, так и из разводящей сети пострадавших территорий.

При проведении анализов проб питьевой воды использовались стандартные методы физико-химического и бактериологического исследования воды, 
регламентированные в ГОСТ Р 51592-2000 «Вода. Общие требования к отбору проб» и ГОСТ Р 51232-98 «Вода питьевая. Общие требования к организации и методам контроля качества».

\section{РЕЗУЛЬТАТЫ И ИХ ОБСУЖДЕНИЕ}

22 декабря 2013 г. в 01.55 на территории Республики Хакасия (с эпицентром в районе села Лукьяновка Алтайского района) в 40 км от города Абакана, в 50 км от Саяно-Шушенской ГЭС произошло землетрясение интенсивностью около 6 баллов по шкале МСК-64, магнитудой 4,9 баллов. На территории Республики Хакасия введен режим чрезвычайной ситуации, установлен региональный уровень реагирования. На заседании КЧС и ПБ при Правительстве Республики Хакасия Управлению Роспотребнадзора по Республике Хакасия поручено обследование водоисточников. Режим чрезвычайной ситуации в Республике Хакасия снят 17.01.2013 г. За данный период проведено обследование 50 источников централизованного хозяйственно-питьевого водоснабжения, расположенных на 11 административных территориях Республики Хакасия (г. Абакан, Алтайский район, г. Черногорск, г. Саяногорск, г. Абаза, Усть-Абаканский, Бейский, Аскизский, Таштыпский, Ширинский, Opджоникидзевский районы) счисленностью населения 486479 человек.

Всего за период с 22.12.2013 г. по 26.12.2013 г. на всех административных территориях республики в рамках государственного санитарно-эпидемиологического надзора из источников централизованного водоснабжения отобрано 129 проб, в т. ч. 62 пробы - на микробиологические, 62 пробы - на санитарнохимические, 5 проб - на радиологические показатели.

По результатам лабораторных исследований 12 проб воды (19,3\%) не соответствовали по санитарно-химическим показателям, а именно: отмечается превышение предельно допустимых концентраций (ПДК) - аммиака в воде из источников централизованного водоснабжения с. Кирба, с. Куйбышево, с. Новотроицкое, д. Новокурск, д. Буденовка, с. Сабинка, с. Новоенисейка в 1,5-8,0 раз (пробы отобраны 24.12.2013 г.). Превышения концентраций нитратов в воде водоисточников с. Новокурск, с. Сабинка - в 1,2-3,0 раза; п. Верхняя Согра, д. Герасимовка, пгт. Усть-Абакан по ул. Шолохова и ул. Щорса и с. Бея - в 1,2-1,5 раза, содержание которых систематически наблюдалось в пределах 50-75 мг/л.

Исследованные образцы проб воды по микробиологическим показателям соответствовали требованиям СанПиН 2.1.4.1074-01 «Питьевая вода. Гигиенические требования к качеству воды централизованных систем питьевого водоснабжения. Контроль качества».

Для исследований по радиологическим показателям отобраны пробы из источника централизованного водоснабжения пгт. Усть-Абакан (ул. Щорса), распределительной сети с. Краснополье, с. Новороссийское, д. Лукьяновка Алтайского района и с. Новотроицкое Бейского района. Данные источники водоснабжения находятся на постоянном контроле. По результатам ранее проведенных исследований в рамках социально-гигиенического мониторинга на протяжении последних 5 лет в их воде отмечается постоянное превышение суммарной альфаактивности от 2,12 до 3,7 Бк/дм3. По результатам лабораторных исследований 5 проб питьевой воды не соответствуют гигиеническим требованиям по показателю альфа-активности. Превышение составляет 10,6-18,5 раза, т. е. находится в пределах среднемноголетних значений. Ранее установлено, что повышенная альфа-активность обусловлена радионуклидами U238, U234. Отношение удельных активностей к их уровням вмешательства находилось в пределах 1,12-1,45, и при данных значениях проведение дополнительных радиозащитных мероприятий не требуется.

В мае - июне 2014 г. на территории Республики Хакасия произошла другая чрезвычайная ситуация, связанная с прохождением снего-дождевого паводка, осложнённого обильным выпадением осадков. 30.05.2014 г. решением КЧС и ПБ при Правительстве Республики Хакасия установлен режим чрезвычайной ситуации, региональный уровень реагирования. 31.05.2014 введен режим чрезвычайной ситуации в регионах СФО, в том числе в Республике Хакасия, федеральный уровень реагирования. Зона ЧС определена в границах территорий 7 муниципальных образований: г. Абакан (дачный массив), г. Абаза, Аскизский, Алтайский, Бейский, Таштыпский и УстьАбаканский районы.

В 22 населенных пунктах подвергся подтоплению 881 жилой дом, где проживали 4213 человек, в т. ч. 1059 детей в возрасте до 14 лет. Было эвакуировано 785 человек, 269 детей до 14 лет, из них в пункты временного размещения (ПВР) - 144 человека (78 детей).

Известно, что, наряду с экономическим ущербом, наводнения оказывают значительное влияние на экологию окружающей среды. Масштабы воздействия определяются интенсивностью, продолжительностью стихийного бедствия. Все это приводит к ухудшению качества почвенного, растительного покровов, среды обитания животных и человека, а также питьевой воды $[3,6,8]$. Поэтому для обеспечения оперативного принятия управленческих решений организован еженедельный мониторинг качества питьевой воды. Была расширена номенклатура исследований.

В целом в паводковый и послепаводковый период лабораторному контролю подверглись 2263 пробы воды централизованного водоснабжения по микробиологическим показателям, 788 проб - по санитарно-химическим показателям. В начальный период ЧС выполнение исследований осуществлялось по сокращенному перечню, преимущественно для контроля микробиологической безопасности питьевой воды. В последующем объем и номенклатура исследований были доведены до оптимального уровня в максимально сжатые сроки. В зависимости от периода паводкового и послепаводкового периода качество воды изменялось следующим образом. Так, в мае доля нестандартных проб по микробиологическим показателям составила 9,8 \%, в период спада паводка, в июне, удельный вест нестандартных 
проб снизился до 3,3 \%. Таким образом, наибольший удельный вес нестандартных проб, отобранных из централизованной сети, по микробиологическим показателям наблюдался в период максимального подъема уровня реки Абакан с 29 мая по 12 июня. В пиковый период паводка удельный вес нестандартных проб по микробиологическим показателям составлял до 65 \% и по санитарно-химическим показателям - до $18 \%$ [2].

В ходе лабораторных исследований питьевой воды в г. Абакане выявлены превышения ПДК железа в разводящей сети в 2 случаях - в 1,3 и 2,4 раза. По микробиологическим исследованиям были обнаружены термотолерантные колиформные бактерии (ТКБ), общие колиформные бактерии (ОКБ) (59 бактерий в 100 мл при норме «не допускается в 100 мл»), при этом общее микробное число (ОМЧ) было увеличено в 1,3 раза. В 3 пробах, отобранных из трубчатых колодцев на территории дач «Орбита» (г. Абакан), выявлены ОКБ и ТКБ при норме «не допускается в 100 мл», в 2 случаях выявлено превышение ОМЧ в 2,7 и 3 раза. К сожалению, регулярные исследования воды из нецентрализованных источников в данном районе города не проводились, и оценить воздействие паводка на изменение состава и качества воды не представляется возможным.

В ходе лабораторных исследований питьевой воды в Бейском районе выявлены превышения гигиенических нормативов в 5 пробах: в 4 пробах - органолептических показателей (цветность, мутность) в пределах 2,2-10,8 раза, железа в 1,6 раза; в 1 пробе - концентрации нитратов в 2,9 раза.

В Алтайском районе выявлены превышения ПДК железа в 1 пробе питьевой воды в 1,2 раза. По микробиологическим исследованиям превышения обнаруживались в 1 пробе из распределительной сети по показателю ОМЧ в 1,3 раза и ОКБ, ТКБ (16 бактерий в 100 мл при норме «не допускается в 100 мл»).

Выявлены превышения ПДК остаточного хлора в Аскизском районе: в 2 пробах - в 18,4 и 116,0 раз. Превышения связаны с проведенным обеззараживанием скважин. Поскольку хлор выраженно влияет на органолептические свойства, употребление такой воды невозможно.

По микробиологическим исследованиям превышения обнаруживались в 7 пробах в разводящей сети Бельтирского психоневрологического интерната по показателям ОКБ, ТКБ, в 8 пробах из децентрализованных источников водоснабжения.

Кроме того, в 2 пробах обнаружено несоответствие органолептического показателя «цветность» от нормативного значения в 1,1 и 1,3 раза.

В ходе лабораторных исследований питьевой воды в г. Абазе выявлены превышения по микробиологическим показателям в 8 пробах, в т.ч. в 1 - из разводящей сети (ОКБ, ТКБ - 105 КОЕ в 100 мл при норме «не допускается», ОМЧ - в 1,6 раза), в 7 - из источников децентрализованного водоснабжения (ОКБ, ТКБ - от 2 до 105 КОЕ в 100 мл при норме «не допускается», ОМЧ (в 2 пробах) - в 1,3 раза).

В ходе лабораторных исследований питьевой воды в Таштыпском районе выявлены превышения по микробиологическим показателям в 4 пробах из источников децентрализованного водоснабжения по показателям ОКБ, ТКБ от 8 до 185 КОЕ в 100 мл при норме «не допускается», ОМЧ (в 2 пробах) - в 1,2 и 1,6 раза.

В ходе лабораторных исследований питьевой воды в Усть-Абаканском районе выявлены превышения по микробиологическим показателям в 7 пробах, в т. ч. в 1 - из разводящей сети (ОКБ, ТКБ - 1 КОЕ в 100 мл при норме «не допускается»), в 6 - из источников децентрализованного водоснабжения по показателям (ОКБ, ТКБ - от 37,3 до более 300 КОЕ в 100 мл при норме «не допускается», ОМЧ (в 5 пробах) - в 3 раза).

Третья ситуация возникла 12 апреля 2015 г.: в результате пожаров, сухой погоды, сильного порывистого ветра более 25 м/с произошли возгорания 1279 домов и 12 социально значимых объектов (6 объектов образования, 4 фельдшерско-акушерских пункта, 1 клуб, 1 летний загородный оздоровительный лагерь) в 38 населенных пунктах 10 муниципальных образований республики. Постановлением Главы Республики Хакасия - Председателем Правительства Республики Хакасия с 13.0012 апреля 2015 г. введен режим чрезвычайной ситуации на всей территории республики, установлен региональный уровень реагирования. По официальным данным в республике пострадали 6442 человека, нарушены условия жизнедеятельности 4586 человек.

За период ликвидации ЧС обследовано 45 источников водоснабжения (100%), исследовано 564 пробы питьевой воды. По результатам лабораторных исследований не соответствуют гигиеническим требованиям $89(15,8 \%)$ проб по санитарно-химическим показателям, 52 (9,2 \%) пробы по микробиологическим показателям, что превышает среднемноголетние значения по Республике Хакасия $(8,1$ \% и 6,4 \% соответственно).

На протяжении трех лет в Республике Хакасия регистрировались различные ЧС, при этом все три происходили в пяти муниципальных образованиях (г. Абакан, Алтайский, Аскизский, Усть-Абаканский, Бейский районы) с численностью населения более 250 тысяч человек; дважды пострадавшими являлись 6 территорий (г. Черногорск, г. Саяногорск, г. Абаза, Ширинский, Орджоникидзевский, Таштыпский районы), где проживает более 200 тысяч человек.

Несоответствие питьевой воды по микробиологическим показателям представляет угрозу возникновения инфекционных заболеваний в каждом конкретном случае $[1,5]$. Эффективность и своевременность принятых профилактических мер подтверждаются и результатами ретроспективного анализа заболеваемости. Эпидемиологическая ситуация в Республике Хакасия по заболеваемости острыми кишечными инфекциями характеризуется как напряженная, однако при возникновении ЧС и в периоды их ликвидации тенденции к росту заболеваемости, в сравнении с предыдущим периодом, а также формирования групповых очагов инфекционных заболеваний не отмечено [2]. 


\section{выводы}

1. Во время ЧС, связанной с прохождением паводка, и в период ликвидации массовых пожаров отмечено ухудшение качества питьевой воды по микробиологическим показателям.

2. Комплекс проводимых мероприятий в период чрезвычайных ситуаций и при ликвидации их последствий позволил не допустить ухудшения санитарно-эпидемиологической ситуации, возникновения вспышечной заболеваемости, связанной с водным фактором.

\section{ЛИТЕРАТУРА REFERENCES}

1. Бадеева Т.В., Грачева М.П., Тихомиров Ю.П., Матвеева Н.А. Качество питьевой воды как фактор риска здоровью населения // Вестник Российской Военномедицинской академии. - 2008. - № 3, Прил. 2. - С. 438.

Badeyeva TV, Gracheva MP, Tikhomirov YP, Matveeva NA (2008). Quality of drinking water as a risk factor for the health of the population [Kachestvo pit'evoy vody kak faktor riska zdorov'yu naseleniya]. Vestnik Rossiyskoy Voenno-meditsinskoy akademii, (3), 438.

2. Государственный доклад «О состоянии санитарно-эпидемиологического благополучия населения в Республике Хакасия в 2014 году». - URL: http://19.rospotrebnadzor.ru/c/document_ library/get_file?uuid=94aaf9e 0 -eeda- 4572 -bbd8$7 \mathrm{~d} 74 \mathrm{f} 9523 \mathrm{dbb} \&$ groupId=10156 (дата обращения 13.03.2016).

State report "On the state of sanitary and epidemiological welfare of the population of the Republic of Khakassia in 2014" [Gosudarstvennyy doklad "O sostoyanii sanitarno-epidemiologicheskogo blagopoluchiya naseleniya v Respublike Khakasiya v 2014 godu"]. Availiable at http://19.rospotrebnadzor.ru/c/document_library/ get_file?uuid=94aaf9e0-eeda-4572-bbd8-7d74f9523dbb\&groupId=10156 (accessed 13 March 2016).

3. Истомина М.Н., Кочарян А.Г., Лебедева И.П. Наводнения: Генезис, социально-экономические и экологические последствия // Водные ресурсы. 2005. - Т. 32, № 4. - С. 389-398.

Istomina MN, Kocharyan AG, Lebedeva IP (2005). Floods: Genesis, socioeconomic and environmental effects [Navodneniya: Genezis, sotsial'no-ekonomicheskie i ekologicheskie posledstviya]. Vodnye resursy, 32 (4), 389-398.
4. Обеспечение санитарно-эпидемиологического благополучия населения при ликвидации последствий наводнения на Дальнем Востоке / Под ред. Г.Г. Онищенко, С.В. Балахонова. - Новосибирск: НаукаЦентр, 2014. - 647 с.

Onishchenko GG, Balakhonov SV (eds.) (2014). Provision of sanitary and epidemiological welfare of the population during flood relief in the Far East [Obespechenie sanitarno-epidemiologicheskogo blagopoluchiya naseleniya pri likvidatsii posledstviy navodneniya na Dal'nem Vostoke], 647.

5. Онищенко Г.Г. Устойчивое обеспечение питьевой водой населения России для профилактики заболеваемости инфекционными и неинфекционными заболеваниями // Гигиена и санитария. - 2003. - № 2. - C. 36.

Onishchenko GG (2003). Stable drinking water supply of the population of Russia for the prevention of communicable and non-communicable diseases [Ustoychivoe obespechenie pit'evoy vodoy naseleniya Rossii dlya profilaktiki zabolevaemosti infektsionnymi i neinfektsionnymi zabolevaniyami]. Gigiena i sanitariya, (2), 36.

6. Носков А.К., Шаракшанов М.Б., Вишняков В.А. Тактические приемы работы специализированных противоэпидемических бригад в различных чрезвычайных ситуациях на территории Сибири и Дальнего Востока // Дальневосточный журнал инфекционной патологии. - 2014. - № 24. - С. 20-24.

Noskov AK, Sharakshanov MB, Vishnyakov VA (2014). Tactics of work of specialized anti-epidemic teams in various emergencies on the territory of Siberia and the Far East [Takticheskie priemy raboty spetsializirovannykh protivoepidemicheskikh brigad $\mathrm{v}$ razlichnykh chrezvychaynykh situatsiyakh na territorii Sibiri i Dal'nego Vostoka]. Dal'nevostochnyy zhurnal infektsionnoy patologii, (24), 20-24.

7. Чрезвычайные ситуации. - URL: http://www. mchs.gov.ru/activities/stats/chrezvichajnie situacii (дата обращения 13.03.2016).

Emergencies [Chrezvychaynye situatsii]. Availiable at http://www.mchs.gov.ru/activities/stats/chrezvichajnie situacii (accessed 13 March 2016).

8. Sinisi L, Aertgeerts R (eds.) (2011). Guidance on water supply and sanitation in extreme weather events, 104.

\section{Сведения об авторах Information about the authors}

Иванова Ольга Вячеславовна - начальник отдела санитарного надзора Управления Роспотребнадзора по Республике Хакасия. (665017, Республика Хакасия, г. Абакан, ул. М. Жукова, 5A-1; e-mail: olvapa@rambler.ru)

Ivanova Olga Vyacheslavovna - Head of the Department of Sanitary Inspection of Directorate of Rospotrebnadzor in the Republic of Khakassia (665017, Republic of Khakassia, Abakan, ul. M. Zhukova, 5A-1; e-mail: olvapa@rambler.ru)

Савченков Михаил Федосович - академикРАН, профессор кафедры общей гигиены ГБОУ ВПО «Иркутский государственный медицинский университет» Минздрава России (664003, г. Иркутск, ул. Красного Bосстания, 1; e-mail: mfs36@mail.ru) Savchenkov Mikhail Fedosovich - Academician of RAS, Professor of the Department of General Hygiene of Irkutsk State Medical University (664003, Irkutsk, ul. Krasnogo Vosstania, 1; e-mail: mfs36@mail.ru)

Романова Татьяна Геннадьевна - руководитель Управления Роспотребнадзора по Республике Хакасия (e-mail: tu@rpnrh.ru) Romanova Tatiana Gennadyevna - Head of Directorate of Rospotrebnadzor in the Republic of Khakassia (e-mail: tu@rpnrh.ru) 